\title{
An Exploration on the Graduate Flexible Employees
}

\author{
Zhao Chongping, Yan Feng \\ Research Department of Chongqing Business Vocational College, Chongqing, China \\ cqszyzcp@163.com
}

Keywords: University graduate, Flexible employment, Characteristics, Countermeasure.

\begin{abstract}
With the enlargement of graduate flexible employment, its category and characteristics have also diversified. Therefore, it is of great importance to optimize and improve relevant policies, social security and educational propaganda to promote the flexible employment of university graduates.
\end{abstract}

With the economic restructuring and employment change, the employment situation has been increasingly strained. Quite a few university graduates have chosen to be flexible employees. In 2013, our research group has made a survey on the social security of flexible employees. It reveals that 34.3 percent college graduates have chosen this employment, which has alleviated employment pressure and promoted graduates' career recognition. However, there are still some relevant problems remaining to be studied.

\section{The reasons of choosing flexible employment}

According to our investigation, 83.2 percent graduates chose flexible employment for they have no better choice, and 13.5 percent graduates made the same choice for they wanted to look for a better one during their flexible employment. Besides, about 3.3 percent graduates consider the flexible employment as "free and willing". Thus, the majority of university graduates are forced to choose to be flexible employees not by their interests.

\section{The form and category of flexible employment}

The form of flexible employment. According to relevant research, the present flexible employment of college graduates can be divided into four kinds: flexible employment of formal sectors, pioneering at the grassroots level, self-employment and export of labour service. The first includes the part-time, short-term and seasonal employment, and the second refers to Opinions on Guiding and encouraging Grassroots Employment of Graduates, issued in 2005 by the State Council, and relevant policies which incite graduates to participate in periodical service and practice in rural areas and urban communities at the grassroots level and western China. The third one, the self-employment, means that the preferential policies encourage graduates to utilize their knowledge, talent, technique and capabilities to raise funds and find collaboration to create value and realize self-employment. And lastly, the export of labour service means that college graduates signed labour contracts with the labour dispatching company, the intermediary, and then are sent to client companies for employment and compensation.

The category of flexible employment. According to our investigation, the college graduates that have chosen to be flexible employees can be divided into the following types: the first is the graduates of higher vocational schools. Due to the reform and exploration on talents training in vocational school in recent years, a large amount of vocational students have been sent to work in lower-level positions. In a certain probation period, there are no formal procedures. On the other hand, most vocational students go to medium and small enterprises and private enterprises for employment and some enterprises do not sign with these students, which has lead to a relatively larger proportion of vocational flexible employees. The second is the college graduates of art. Because of the particularity of their job, many graduates prefer free and loose work environment, such as free-lancer writers, artistic design and private tutors. The third is the college graduates who 
have difficulty in finding a job and are forced to do some temporary work.

The distribution of flexible employment. Due to the difficulty of doing flexible employment investigation, it is uneasy to make quantitative and standardized census. There has been conservative estimation on current flexible employment of Chinese university graduates. From the distribution area point of view, there is area and industrial imbalance for the current graduate flexible employment: the developed areas is often characterised by a high admission in the labour market and there is a corresponding high flexible employment rate of college graduates, while the remote, under-developed and ethnic minority areas have a low flexible employment rate as their brain drain is serious. It is obvious that the large part of the flexible employment concentrates in metropolis and eastern China. From the industrial distribution point of view, due to the serious harm of monopoly in the power sector, financial insurance, radio, TV and film, the proportion of graduates' flexible employment is low. In the labour-intensive industry which there is poor labour condition, intensive labour and temporary work, the migrant workers occupy a high proportion and the percentage of graduates' flexible employment is not high, such as the extractive industry, textile, construction, transportation, warehousing and catering industries. On the contrary, there is flexible employment mechanism and free working environment in newly-rising enterprises like new high-tech and information consultant companies, and thus many mid- and high-tier talents are attracted here and the percentage of graduates' flexible employment is relatively high(Teng Yuanjie, 2009).

\section{The whole situation of graduate flexible employment}

The recognition of flexible employment. The first problem to be changed is the recognition. In the traditional employment viewpoints, the work of state-owned enterprises and public institutions is always considered as real employment, the flexible employment is an unwilling choice before the "real employment". On the other hand, it is hard for the rural families to foster a college graduate. When their children choose an unstable profession without protection, both the parents and children often have difficulty to accept this choice. Despite the central and local governments have formulated several preferential policies for college graduates' flexible employment, the students and their parents have little enthusiasm for participate in flexible employment.

The compensation of flexible employment. The general compensation level of flexible employment is relatively low. As the market economic system is unsound, the action and behaviour of most private enterprise are not regulated and restricted. The newly graduated students have no working experiences and thus often receive fair compensation. Besides, there are no more concrete employment policies except the minimum wage standard so college graduates find it difficult to rely on legal protection and safeguard.

The labour relation of flexible employment. The reason for the low proportion of labour contract is often because the employers are unwilling to fulfil the labour standards stipulated in law and regulations. Some employers, such as the self-employed businessmen, have no subject qualification and are unable to establish legal labour relations with employees. Consequently, the flexible employment of college graduates is characterized by great instability. The labourers often recycle among employment, unemployment and re-employment.

The social security of flexible employment. In China, there is no corresponding social security for flexible employees, including the unemployment, medical and endowment insurances. According to Social Insurance Law, the enterprises must pay for employees' social security while the employees of many small private enterprises are not covered by social insurance. Meanwhile, the college graduates who are young and strong have poor insurance consciousness and haven't signed labour contracts, so they have no corresponding social security when the occupational injury occurred.

The policy environment of self-employment. At present, the development of medium and small enterprises has been tripped in a dilemma. Firstly, it is difficult to acquire fiscal support. Due to the lack of credit and guarantee system of medium and small enterprises and individuals, it is difficult for them to acquire loans. Secondly, there are few preferential taxation policies for flexible 
employees, and the cumbersome process and high fees have led to the excessive cost for starting and running enterprises. Thirdly, it is difficult to find a management place in metropolice for the rent of formal location is high. Fourthly, the lack of systematic consultancy and pioneering training. Therefore, the policy environment of flexible employment remains to be improved.

\section{How to promote the graduate flexible employment}

As a special group, the college graduates of flexible employment has been increasing continually. Although there is no concise number, the expansion of the population of college graduates in recent years has showed the great development space of flexible employment. According to Circular of the State Council on further Improving the Employment of University Graduates, the employment of college graduates is of great importance to the development of a powerful country rich in human resources and innovation, the security and livelihood of civilians, the harmony and stability of society and the sustainable and healthy development of economy. Therefore, it is necessary to scale up efforts and promote the employment quality of college graduates.

The high attention and sound law and regulation. In market economy, our government should strengthen macro control and make more efforts to standardize the labour market and create a fair environment for employment. Firstly, the importance on flexible employment should be elevated to a legal height. Our government should formulate and issue laws and regulations which will guarantee the status and importance of flexible employment legally, protect the flexible employees' rights and interests and ensure the management of their social insurance be implemented on legal basis. Secondly, it is necessary to formulate the preferential and supportive policy aiming at flexible employees, which will strengthen the management and supervision of employers and ensure the legal rights and interests of flexible employees be efficiently protected. Thirdly, the government should establish a flexible market in order to promote the development of graduate flexible employment. The covering of graduate flexible employment of college graduates into development plan of higher education will guarantee the status of flexible employment and promote the market environment of its growth. Fourthly, the self-employment and flexible employment of university graduates should be supported by preferential policies. For example, capable local governments can reduce the tuition or pay for educational loans if graduates work in rural areas or choose to be flexible employees. Fifthly, it is necessary to speed the legalization of flexible employment market to standardize the order of human resources market and guarantee the basic rights and interests of flexible employees. A fair and open competitive environment and a human resources market will provide legal assistance for flexible employees and strengthen the management of employers.

To encourage the employment diversification and social security. With the economic restructuring and acceleration, the diversification of labour market. Meanwhile, the construction and improvement of social security system and national security policy appropriate for graduates will gradually enlarge the coverage of unemployment insurance and the social security of graduates will be lawful. The social security of college graduates can be implemented according to different groups. For graduates who have chosen to be self-employed or employed by formal enterprises and institutions, their complete social security should be established as they have relatively long labour relation and stable position. Besides, the minimum wage system should be established as soon as possible, thus the graduates' basic living conditions will be guaranteed. For the payment of social security, the procedures should be simplified. Thirdly, graduates should be encouraged to choose grass-roots job, self-employment or work in middle and western China. For enterprises and institutions which recruit college students for employment practice and issue them living subsidies, the enterprises and institutions can apply for subsidy of employment practice to local human resources and social security department.

To strengthen and optimize the guidance of flexible employment. As a systematic project, the flexible employment should be supported by school guidance. From the students' entrance, adequate preparation should be started, including students' knowledge, capability, viewpoints, technique and psychology. For this purpose, the propaganda should be conducted in order to 
popularize the definition, function and significance of flexible employment and encourage students to seize the job opportunity and flexible employing units to recruit more graduates. Thirdly, to actively conduct flexible employment education. In order to adapt to the new situation of flexible employment, colleges and universities should reform their original teaching contents and approach and innovate their talents training. Besides, it is necessary to strengthen the quality-oriented education, that is, the education focused on multi-disciplinary knowledge and develop students' ability of learning and renewing knowledge according to the advancement of society. In conclusion, the informal employment has turned into the main channel for graduates' employment due to the formation and growth of socialist market economy. It is necessary to strengthen the efforts to educational propaganda, change the employment viewpoints of society, families and students, encourage graduates to choose and adjust their employment orientation and integrate flexible employment and their career plan to realize the optimization of employment.

(Note: this paper is part of the complementary research findings of the 2012 projects - The Current Problems and Countermeasures of Social Security of Flexible Employees in Chongqing, No.2012YBGL134, and The System Construction of Social Security of Flexible Employees in Chongqing, No.KJ133601)

\section{References}

[1] MyCOS Research Institute: The employment report of Chinese Graduates in 2010(employment bluebook), social sciences academic press, 2010

[2] Yang Chaonan, Thoughts on how to promote the flexible employment of graduates: Journal of Changjiang University(Social Science Edition) Vol. 9 (2011), p. 154-155

[3] Yu Huanjiu, The current problems and countermeasure of graduates' flexible employment: Work \& Study Abroad Vol. 6 (2010), p. 53-54

[4] Teng Yuanjie, The existing problems and countermeasure of graduates' flexible employment: Journal of Jilin Technology and Business Institute Vol. 9 (2009), p. 117-119

[5] Ye Fengjie, The management of graduates' flexible employment: Science \& Technology Information Vol. 20 (2008), p. 148-149

[6] Chen Yahong, An analysis on current graduates' flexible employment: Journal of Hunan Taxation technical college Vol. 23 (2010), p. 61-63

[7] Zhong Lan, Practice and experience of promoting graduates' flexible employment:Science \& Technology Information Vol. 12 (2010), p. 76-79 